\title{
Stress Hyperglycemia Is Independently Associated with Persistent Organ Failure in Acute Pancreatitis
}

\author{
Xinmin Yang ${ }^{1} \cdot$ Ruwen Zhang ${ }^{1}$ Tao Jin ${ }^{1} \cdot$ Ping Zhu $^{1} \cdot$ Linbo Yao $^{1} \cdot$ Lan Li $^{1} \cdot$ Wenhao Cai ${ }^{1,2} \cdot$ Rajarshi Mukherjee $^{2}$. \\ Dan $\mathrm{Du}^{3} \cdot$ Xianghui Fu ${ }^{4}$. Jing Xue ${ }^{5} \cdot$ Reynaldo Martina ${ }^{6} \cdot$ Tingting Liu $^{1} \cdot$ Sayali Pendharkar ${ }^{7}$. Anthony R. Phillips ${ }^{7,8}$. \\ Vikesh K. Singh ${ }^{9} \cdot$ Robert Sutton $^{2} \cdot$ John A. Windsor ${ }^{7} \cdot$ Lihui Deng $^{1} \cdot$ Qing Xia $^{1} \cdot$ Wei Huang ${ }^{1}$
}

Received: 4 December 2020 / Accepted: 30 March 2021 / Published online: 3 May 2021

(c) The Author(s) 2021

\begin{abstract}
Background/Aims Stress hyperglycemia is common in critical illness but it has not been clearly studied in patients with acute pancreatitis (AP). This study aimed to investigate the specific blood glucose (BG) level that defines stress hyperglycemia and to determine the impact of stress hyperglycemia on clinical outcomes in AP patients.

Methods AP patients admitted $\leq 48 \mathrm{~h}$ after abdominal pain onset were retrospectively analyzed. Patients were stratified by pre-existing diabetes and stress hyperglycemia was defined using stratified BG levels for non-diabetes and diabetes with clinical outcomes compared.

Results There were 967 non-diabetic and 114 diabetic (10.5\%) patients met the inclusion criteria and the clinical outcomes between these two groups were not significantly different. In non-diabetes, the cut-off BG level of $\geq 180 \mathrm{mg} / \mathrm{dl}$ was selected to define stress hyperglycemia with an 8.8-fold higher odds ratio for persistent organ failure (POF) (95\% CI 5.4-14.3; $P<0.001)$. For diabetes, $\geq 300 \mathrm{mg} / \mathrm{dl}$ was selected with a 7.5 -fold higher odds ratio for POF $(95 \%$ CI $1.7-34.3 ; P=0.009)$. In multivariable logistic regression, stress hyperglycemia was independently associated with POF, acute necrotic collection, major infection and mortality. The combination of BG and systemic inflammatory response syndrome (SIRS) score in predicting POF was better than SIRS or Glasgow score alone.

Conclusions This study identifies a cut-off BG level of $\geq 180 \mathrm{mg} / \mathrm{dl}$ and $\geq 300 \mathrm{mg} / \mathrm{dl}$ was optimal to define stress hyperglycemia for non-diabetic and diabetic AP patients, respectively. There was a significant relationship between stress hyperglycemia and adverse clinical outcomes.
\end{abstract}

Keywords Acute pancreatitis $\cdot$ Blood glucose $\cdot$ Stress hyperglycemia $\cdot$ Diabetes mellitus $\cdot$ Persistent organ failure $\cdot$ Receiver operating characteristic curve

Wei Huang

dr_wei_huang@scu.edu.cn

Qing Xia

xiaqing@medmail.com.cn

1 Department and Laboratory of Integrated Traditional Chinese and Western Medicine, Sichuan Provincial Pancreatitis Centre and West China-Liverpool Biomedical Research Centre, West China Hospital, Sichuan University, No. 37 Wannan Guoxue Alley, Chengdu 610041, Sichuan Province, China

2 Liverpool Pancreatitis Research Group, Liverpool University Hospitals NHS Foundation Trust and Institute of Translational Medicine, University of Liverpool, Liverpool, UK

3 West China-Washington Mitochondria and Metabolism Center, West China Hospital, Sichuan University, Chengdu, China
4 Division of Endocrinology and Metabolism, State Key Laboratory of Biotherapy, West China Hospital, Sichuan University and Collaborative Innovation Center of Biotherapy, Chengdu, China

5 State Key Laboratory of Oncogenes and Related Genes, Stem Cell Research Center, Ren Ji Hospital, School of Medicine, Shanghai Jiao Tong University, Shanghai, China

6 Biostatistics and Clinical Trials, Department of Oncology, University of Cambridge, Cambridge, UK

7 Surgical and Translational Research Centre, Faculty of Medical and Health Sciences, University of Auckland, Auckland, New Zealand

8 Applied Surgery and Metabolism Laboratory, School of Biological Sciences, University of Auckland, Auckland, New Zealand

9 Pancreatitis Center, Division of Gastroenterology, Johns Hopkins Medical Institutions, Baltimore, USA 


\section{Introduction}

Acute pancreatitis (AP) is one of the most common gastrointestinal disorders resulting in urgent hospital admission, and frequent readmissions [1]. The global incidence of AP is $30-40$ per 100,000 person-years and is increasing worldwide [1,2]. While biliary and alcohol excess are the most prevalent etiologies in Western countries and Japan [3], hypertriglyceridemia (HTG)-associated AP (HTG-AP) is becoming increasingly common in China [4]. Further, the mortality remains high $(>30 \%)$ in patients with severe AP (SAP), defined as having persistent organ failure (POF) [5]. Yet, to date, there are no internationally accepted and effective pharmacological interventions for treating AP in spite of numerous clinical trials [6] and advances in basic research [7].

Impaired glucose metabolism has long been associated with acute and critical illness. Transient hyperglycemia, also termed stress hyperglycemia or stress-induced hyperglycemia, is usually found in patients without known preexisting diabetes [8]. In myocardial infarction [9], acute ischemic stroke [10], and perioperative patients [11], admission stress hyperglycemia is directly correlated with increased mortality or morbidity. Early transient hyperglycemia has been linked with adverse clinical outcomes and has also been incorporated in Ranson and Glasgow prognostic scores for AP [12]. However, the definition of stress hyperglycemia varies in different diseases. There is no clear definition of stress hyperglycemia for AP patients with damage to an organ that has a central role in glucose regulation. Diabetes mellitus (DM), characterized by hyperglycemia and insulin resistance [13], is a known independent risk factor for developing AP $[14,15]$. While co-existing DM is frequently observed in patients with AP, the effect of stress hyperglycemia on clinical outcomes in patients with and without pre-existing diabetes remains undetermined. This study investigated the relationship of pre-existing DM, and stress hyperglycemia with clinical outcomes of AP.

\section{Methods}

\section{Study Population}

The current study was designed, conducted and reported as per StrengThening the Reporting of OBservational studies in Epidemiology (STROBE) guidelines [16]. Consecutive AP patients admitted to the West China Hospital of Sichuan University from 1 September 2009 to 30 September 2013 were screened for eligibility. The ethics committee and institutional review boards approved the study (No. 123) with an exemption of consent for available anonymized clinical data analyzed in this study.

All patients diagnosed with AP according to Revised Atlanta Classification (RAC) [5] were scrutinized. Patients were included in the study if they met the following criteria: admitted with abdominal pain for $<48 \mathrm{~h}$ and were $18-80$ years of age.

Patients were excluded from the study if they had incomplete data for admission blood glucose (BG) levels, had an admission hypoglycemia (BG levels $<70 \mathrm{mg} / \mathrm{dl}$ ) [17], had glucocorticoids before admission, were pregnant or breast feeding, had trauma, chronic pancreatitis or tumor as etiologies, and/or had advanced comorbidities (congestive heart failure 3-4 or unstable coronary heart disease, end stage lung diseases, chronic kidney disease stage 4-5, liver cirrhosis with modified Child-Pugh grade 2-3, malignancy or immune deficiency).

\section{Definitions}

HTG-AP was defined as serum triglyceride (TG) level $\geq 500 \mathrm{mg} / \mathrm{dl}$ on admission after ruling out common etiologies $[18,19]$. Definitions for biliary, alcohol associated, and other etiologies were reported in our previous work [19, 20]. Pre-existing DM was diagnosed based on disease and medicine history, or serum glycated hemoglobin (HbA1c; $\geq 6.5 \%$ or $48 \mathrm{mmol} / \mathrm{mol}$ ) as per American Diabetes Association (ADA) criteria [17]. Normoglycemia was defined as $\mathrm{BG} \geq 70-126 \mathrm{mg} / \mathrm{dl}$ or $\mathrm{BG} \geq 70-180 \mathrm{mg} / \mathrm{dl}$ for non-diabetic and diabetic patients, respectively. The BG data used in this study were derived from the first blood biochemistry analysis of patients who presented at emergence department and very few were obtained at general ward.

\section{Management of Hyperglycemia}

The protocols for the early treatment of AP patients followed the practice guidelines of China [21] and American Gastroenterological Association (AGA) [22]. Short acting insulin was infused at a rate of $0.05-0.1 \mathrm{U} / \mathrm{kg} / \mathrm{h}$ when $\mathrm{BG}$ levels were very high $(\geq 300 \mathrm{mg} / \mathrm{dl})$ regardless of prior DM status or whether patients received intensive care. Fingertip BG levels were monitored at hourly interval or less. The rate of insulin infusion was maintained if an average drop of BG level at $36-54 \mathrm{mg} / \mathrm{dl} / \mathrm{h}$ was observed. The rate was increased if BG levels did not decrease or if they increased, while it was decreased or discontinued when BG levels dropped more quickly or hypoglycemia occurred. When BG levels were reduced to below $250 \mathrm{mg} / \mathrm{dl}$, insulin (4-6 U insulin in $500 \mathrm{ml}$ glucose solution intravenously) was continuously administered to maintain target BG levels of $140-180 \mathrm{mg} /$ dl with monitoring of fingertip BG levels every 4-6 h [23]. 


\section{Study Variables and Outcome Measures}

Details for data collection were reported previously in our studies $[19,20]$. The manual data collection process followed standard operating procedures (WH and RS) by experienced medical students (XY, RZ, LY, and WC) or attending doctors (LL) with subsequent quality check by more senior doctors (TJ and LD). Study variables included age, gender, time to hospital admission, alcohol consumption history, comorbidities, referral status, etiology, admission indices (lipid profile and clinical severity scores), pancreatic imaging, microbiology and necrosectomy (and/or percutaneous drainage) $[19,20]$. The primary outcome measure was development of POF, defined as at least one of the systems (respiratory, cardiovascular, or renal) having Sequential Organ Failure Assessment (SOFA) score $\geq 2$ and lasting $\geq 48 \mathrm{~h}$ [24]. Secondary outcome measures included acute necrotic collection (ANC), major infection (presence of infected pancreatic necrosis, sepsis and/or pneumonia), and mortality. ANC was diagnosed when imaging reports from enhanced computerized tomographic scans clearly indicated the presence of "pancreatic necrosis or peripancreatic necrosis". In minority of the cases when this was equivocal, an experienced abdominal radiologist reviewed the scans and defined ANC as containing heterogenous contents (necrotic tissue with fluid) in pancreatic parenchyma and/or peripancreatic tissues according to the RAC imaging criteria [5]. Infected pancreatic necrosis was defined by microbiological diagnosis of pancreatic infection after the first sampling from drainage or debridement, or highly suspicion of infection that eventually required necrosectomy in the absence of prior aspiration or drainage to confirm infection [20].

Categorical data are expressed as number with percentages and compared using Chi-square test (or Fisher's test). Continuous data are displayed as medians with interquartile ranges (IQR) and compared using Mann-Whitney $U$ test. Multivariate logistic regression analysis was used to report categorical outcome measures and expressed as odds ratios (ORs) with 95\% confidence intervals (CI). In multivariate logistic regression, each comparison of outcomes was adjusted by baseline covariates that were of important clinical significance. These covariates included age $(>60$ vs. $\leq 60$ years old) [12], gender (male vs. female), Charlson comorbidity index, pain to admission time [19], transfer status [19], and TG with appropriate cut-off values suggested by previous publications. Receiver operating characteristic (ROC) curves were constructed for predictive variables, and the area under the curve (AUC) with 95\% CI was calculated. The combination of two or more variables was assessed by logistic regression model to generate a combined variable and calculated by ROC. Statistical differences between AUC were tested using the DeLong method. A two-sided $P<0.05$ was considered statistically significant. Statistical analyses were performed using SPSS ${ }^{\circledR} 22.0$ (IBM, Armonk, New York, USA).

\section{Results}

\section{Characteristics of Patients With and Without Pre-existing DM}

The patient selection process is shown in Fig. 1. Of a total of 2935 patients screened and 1081 met the inclusion criteria. There were 967 non-diabetic patients and 114 diabetic patients with a proportion of $10.5 \%$. The baseline parameters and clinical outcomes of patients with and without preexisting diabetes are shown in Tables 1 and 2, respectively. There was no significant difference in age, gender, time to admission, referral and etiology between patients with and without pre-existing DM. Patients with pre-existing DM had higher admission BG and TG levels and increased clinical severity scores (Table 1), while the clinical outcomes were not significantly different between diabetic and non-diabetic patients after adjusting for baseline parameters (Table 2).

\section{Clinical Outcomes Based on Different Definitions in Patients Without DM}

Considering that the significant impact of pre-existing DM on admission BG levels, the subsequent analyses were conducted respectively in patients with or without comorbid DM. The distribution of BG in the non-diabetic and diabetic populations is shown in Fig. 2. In the non-diabetic population, stress hyperglycemia was defined as $\geq 126, \geq 140$, $\geq 180$, and $\geq 200 \mathrm{mg} / \mathrm{dl}$ based on previous studies of acute and critical illness. And a total of 682 (70.5\%), 579 (59.9\%), 366 (37.8\%), and 289 (29.9\%) patients were classified as non-pre-existing diabetic patients with stress hyperglycemia, respectively. With the upgrade of cut-off values, the proportion of POF, ANC, major infection and mortality increased (Fig. 3). After adjusting for baseline parameters, the multivariate adjusted ORs showed a gradual increase of POF, ANC, major infection and mortality in patients with normoglycemia and with different stress hyperglycemia definitions (Fig. 3). Notably, there was an obvious deterioration in the definition of $\geq 180 \mathrm{mg} / \mathrm{dl}$ compared with those $\geq 126 \mathrm{mg} / \mathrm{dl}$ and $\geq 140 \mathrm{mg} / \mathrm{dl}$. Patients with stress hyperglycemia ( $\geq 180 \mathrm{mg} / \mathrm{dl}$ ) had an 8.8 -fold higher OR of POF (95\% CI 5.4-14.3, $P<0.001$ ), 4.5-fold higher OR of ANC (95\% CI 2.7-7.5, $P<0.001$ ), 3.4-fold higher OR of major infection (95\% CI 2.0-5.6, $P<0.001)$ and 28.8-fold higher OR of mortality (95\% CI 3.9-213, $P=0.001$ ). According to the ROC curve analysis, a BG of $155 \mathrm{mg} / \mathrm{dl}$ was identified as the cut-off for POF outcomes, with AUCs of 0.73 (95\% CI 0.7-0.75, $P<0.001$; Supplementary Fig. S1). Therefore, 
Fig. 1 Patient selection flow chart. $A P$ acute pancreatitis, $C P$ chronic pancreatitis

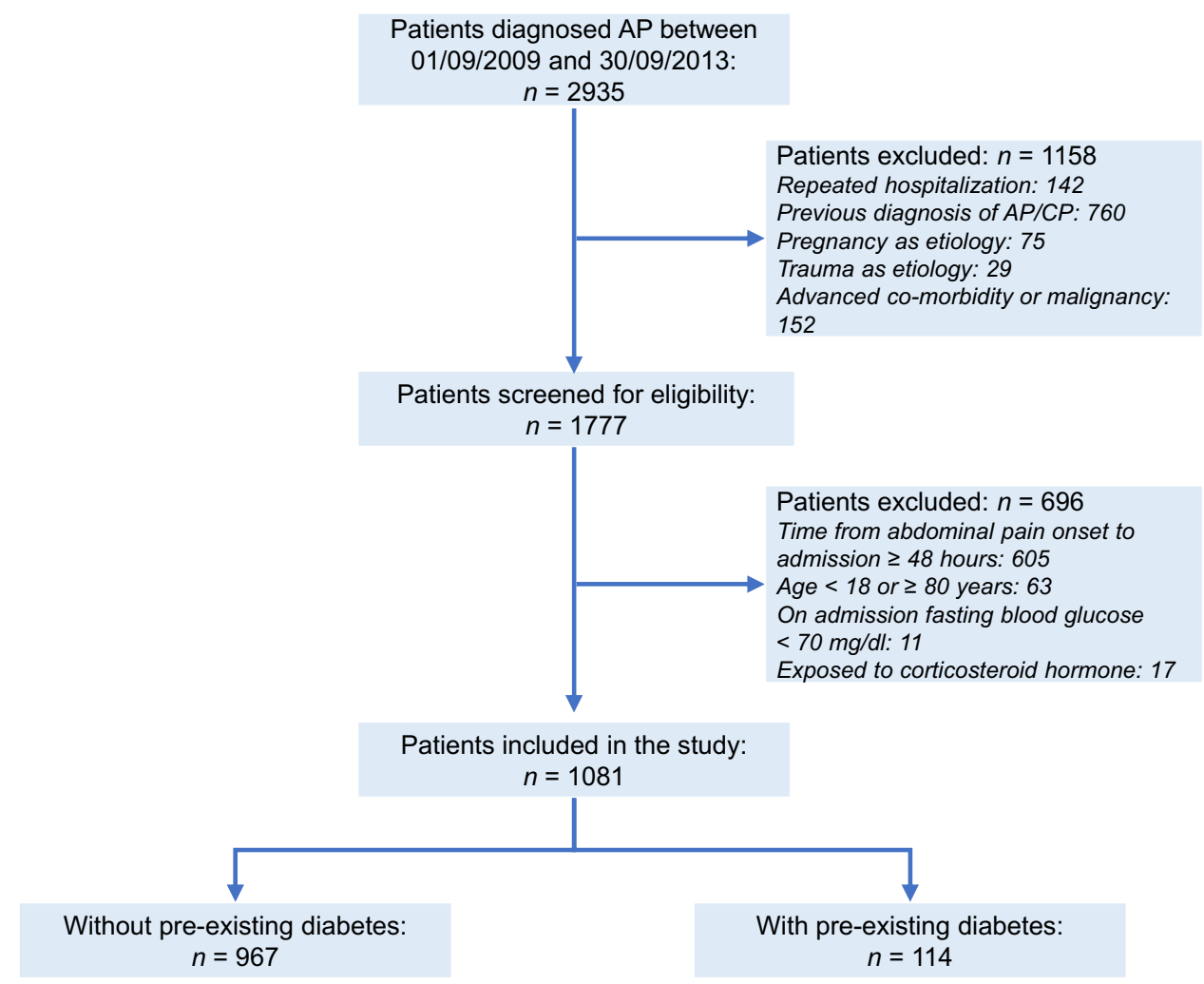

Table 1 Baseline characteristics of patients stratified by pre-existing diabetes

\begin{tabular}{|c|c|c|c|c|}
\hline Parameters & All $(n=1081)$ & No pre-existing DM $(n=967)$ & Pre-existing DM $(n=114)$ & $P$ value \\
\hline Age, years, median (IQR) & $46(38-57)$ & $45(38-56)$ & $47(40-60)$ & 0.050 \\
\hline Sex, male, $n(\%)$ & $656(60.7)$ & $584(60.4)$ & $72(63.2)$ & 0.568 \\
\hline Charlson comorbidity index, median (IQR) & $1(0-1)$ & $1(0-1)$ & $2(2-2)$ & $<0.001$ \\
\hline Time to admission, hours, median (IQR) & $24(17-32)$ & $24(17-32)$ & $25(18-32)$ & 0.327 \\
\hline Referral, $n(\%)$ & $862(79.7)$ & $771(79.7)$ & $91(79.8)$ & 0.981 \\
\hline Etiology, $n(\%)$ & & & & 0.736 \\
\hline Biliary & $452(41.8)$ & $407(42.1)$ & $45(39.5)$ & 0.592 \\
\hline HTG-associated & $289(26.7)$ & $254(26.3)$ & $35(30.7)$ & 0.312 \\
\hline Alcohol excess & $29(2.7)$ & $27(2.8)$ & $2(1.8)$ & 0.760 \\
\hline Mixed $^{\mathrm{a}}$ & $104(9.6)$ & $91(9.4)$ & $13(11.4)$ & 0.495 \\
\hline Others or unknown & $207(19.1)$ & $188(19.4)$ & 19 (16.7) & 0.476 \\
\hline \multicolumn{5}{|l|}{ Laboratory makers, median (IQR) } \\
\hline Glucose $(\mathrm{mg} / \mathrm{dl})$ & $160.6(120.8-228.2)$ & $153.7(117.9-216.0)$ & $252.4(181.8-318.8)$ & $<0.001$ \\
\hline $\mathrm{TG}(\mathrm{mg} / \mathrm{dl})$ & $201.1(90.4-894.9)$ & $182.5(85.1-817.8)$ & $582.1(138.2-1537.2)$ & $<0.001$ \\
\hline \multicolumn{5}{|l|}{ Clinical severity scores, median (IQR) } \\
\hline SIRS & $2(1-3)$ & $2(1-3)$ & $2(1-3)$ & 0.635 \\
\hline Glasgow & $2(1-3)$ & $1(1-2)$ & $2(1-3)$ & $<0.001$ \\
\hline
\end{tabular}

$D M$ diabetes mellitus, IQR interquartile range, $H T G$ hypertriglyceridaemia, $T G$ triglycerides, SIRS systemic inflammatory response syndrome

${ }^{\mathrm{a}}$ Two or more aetiology factors co-existed 
Table 2 Clinical outcomes of patients stratified by pre-existing diabetes

\begin{tabular}{llllll}
\hline Parameters & $\begin{array}{l}\text { No pre-existing diabe- } \\
\text { tes }(n=967)\end{array}$ & $\begin{array}{l}\text { Pre-existing diabetes } \\
(n=114)\end{array}$ & $P$ value & Adjusted OR $(95 \% \text { CI })^{\text {a }}$ & Adjusted $P$ value \\
\hline POF, $n(\%)$ & $291(30.1)$ & $46(40.4)$ & 0.025 & $1.30(0.84-1.99)$ & 0.236 \\
ANC, $n(\%)$ & $193(20)$ & $29(25.4)$ & 0.171 & $1.30(0.80-2.09)$ & 0.287 \\
Major infection, $n(\%)$ & $140(14.5)$ & $18(15.8)$ & 0.708 & $1.01(0.58-1.76)$ & 0.979 \\
Mortality, $n(\%)$ & $53(5.5)$ & $6(5.3)$ & 0.923 & $0.75(0.31-1.83)$ & 0.526 \\
\hline
\end{tabular}

$O R$ odds ratio, $C I$ confidence interval, $P O F$ persistent organ failure, $A N C$ acute necrotic collection

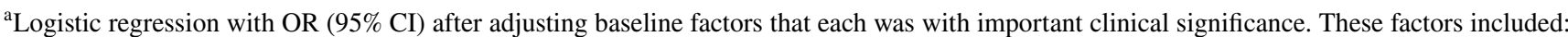
age, gender, Charlson comorbidity index (values were reduced for 1 point for pre-existing diabetes), time to admission, referral status, and admission triglyceride levels

\section{A No pre-existing diabetes}

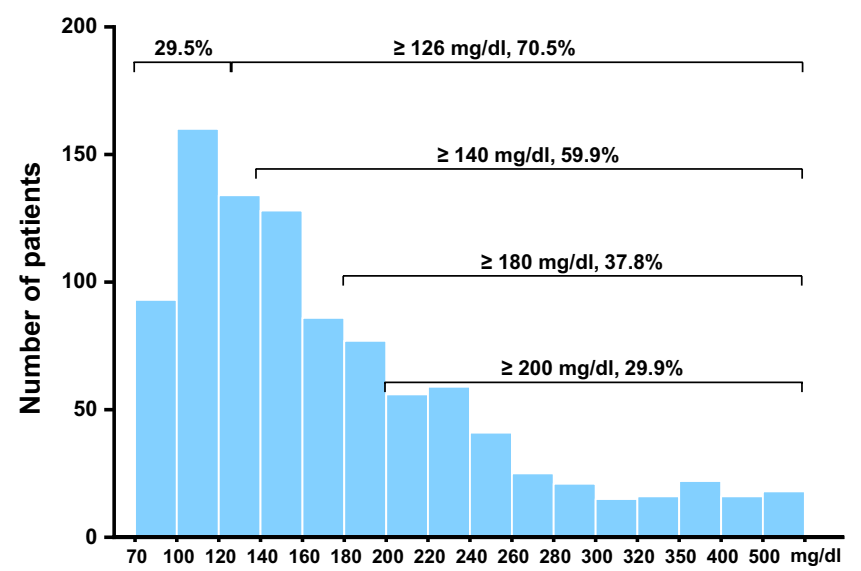

\section{B Pre-existing diabetes}

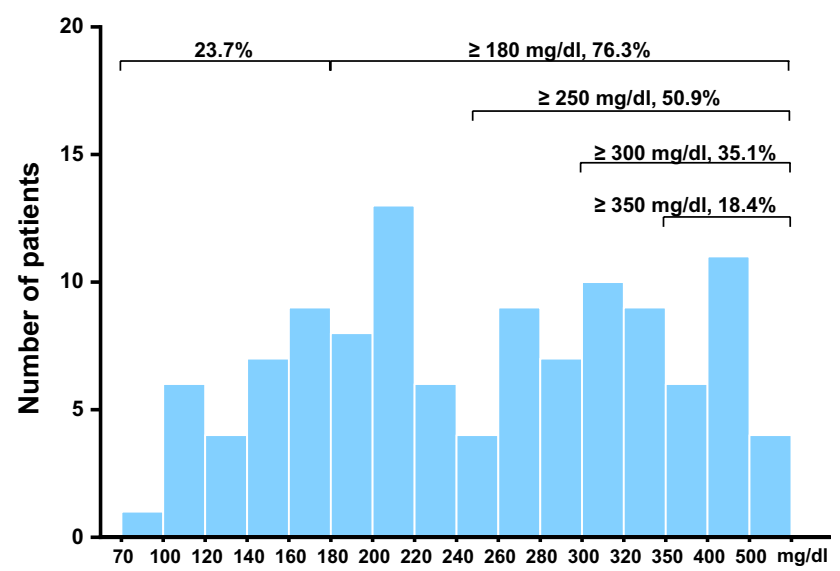

Fig. 2 Distribution of blood glucose in the non-diabetes (a) and diabetes (b)

a cut-off BG level of $\geq 180 \mathrm{mg} / \mathrm{dl}$ was selected to provide a better definition of stress hyperglycemia in AP patients without pre-existing DM.

\section{Clinical Outcomes Based on Different Definitions in Patients with DM}

In the diabetic population, stress hyperglycemia was defined as $\geq 180, \geq 250, \geq 300$, and $\geq 350 \mathrm{mg} / \mathrm{dl}$ based on previous studies, and a total of 87 (76.3\%), 58 (50.9\%), 40 (35.1\%), and $21(18.4 \%)$ patients were classified as pre-existing DM patients with stress hyperglycemia, respectively (Fig. 2). There were also an increasing proportion of POF as the upgrade of cut-off values. In the definition of $\geq 300 \mathrm{mg} /$ $\mathrm{dl}$, patients with stress hyperglycemia had a 7.5-fold higher OR of POF (95\% CI 1.7-34.3, $P=0.009$ ) after adjusting for baseline parameters (Fig. 3). There was no statistical difference in different definitions of major infection, ANC and mortality (data not shown). According to the ROC curve analysis, a BG of $295 \mathrm{mg} / \mathrm{dl}$ was identified as the cut-offs for POF outcomes, with AUCs of 0.72 (95\% CI 0.62-0.8,
$P<0.001$; Supplementary Fig. S1). Therefore, a cut-off BG level of $\geq 300 \mathrm{mg} / \mathrm{dl}$ was selected to provide a better definition of stress hyperglycaemia in AP patients with preexisting DM.

\section{Multivariate Analysis}

In order to verify whether stress hyperglycemia was an independent risk factors for AP adverse outcomes, multivariate logistic analysis was performed in all patients. These results are shown in Table 3. Age $>60$ years old, male, referral status, time to admission $>1$ day, Charlson comorbidity index and stress hyperglycemia were all independent risk factors for POF (all $P<0.05$ ). Referral status, time to admission $>1$ day and stress hyperglycemia were all independent risk factors for ANC (all $P<0.05$ ). Age $>60$ years old, male, referral status and stress hyperglycemia were all independent risk factors for major infection (all $P<0.05$ ). Age $>60$ years old, admission $\mathrm{TG} \geq 500 \mathrm{mg} / \mathrm{dl}$ and stress hyperglycemia were all independent risk factors for mortality (all $P<0.05$ ). These results highlight that stress hyperglycemia was 
A No pre-existing diabetes

\begin{tabular}{llcc}
\hline $\begin{array}{l}\text { Admission BG levels } \\
\mathbf{m g} / \mathbf{d l}\end{array}$ & $\begin{array}{l}\text { POF, } \\
\boldsymbol{n}(\%)\end{array}$ & $\begin{array}{c}\text { Adjusted OR } \\
\mathbf{( 9 5 \% ~ C l )}\end{array}$ & $\begin{array}{c}\text { Adjusted } \\
\boldsymbol{P} \text { value }\end{array}$ \\
\hline$\geq 70$ to $126(n=285)$ & $25(8.8)$ & 1 (reference) & - \\
$\geq 126(n=682)$ & $266(39.0)$ & $6.16(3.93-9.65)$ & $<\mathbf{0 . 0 0 1}$ \\
$\geq 140(n=579)$ & $239(41.3)$ & $6.75(4.28-10.66)$ & $<\mathbf{0 . 0 0 1}$ \\
$\geq 180(n=366)$ & $174(47.5)$ & $8.82(5.44-14.29)$ & $<\mathbf{0 . 0 0 1}$ \\
$\geq 200(n=289)$ & $145(50.2)$ & $10.28(6.20-17.06)$ & $<\mathbf{0 . 0 0 1}$ \\
\hline
\end{tabular}

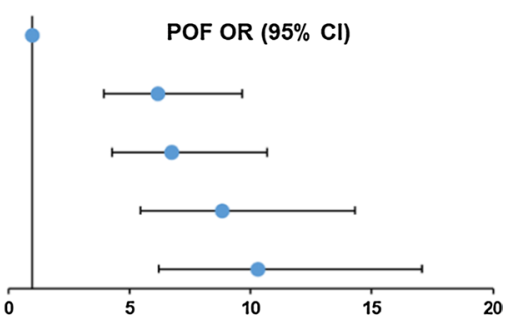

\begin{tabular}{llcc}
\hline $\begin{array}{l}\text { Admission BG levels, } \\
\mathbf{m g} / \mathbf{d l}\end{array}$ & $\begin{array}{l}\text { ANC, } \\
\boldsymbol{n}(\%)\end{array}$ & $\begin{array}{c}\text { Adjusted OR } \\
\mathbf{( 9 5 \% ~ C l )}\end{array}$ & $\begin{array}{c}\text { Adjusted } \\
\boldsymbol{P} \text { value }\end{array}$ \\
\hline$\geq 70$ to $126(n=285)$ & $23(8.1)$ & $1($ reference $)$ & - \\
$\geq 126(n=682)$ & $170(24.9)$ & $3.50(2.18-5.62)$ & $<\mathbf{0 . 0 0 1}$ \\
$\geq 140(n=579)$ & $153(26.4)$ & $3.72(2.31-6.01)$ & $<\mathbf{0 . 0 0 1}$ \\
$\geq 180(n=366)$ & $114(31.1)$ & $4.53(2.74-7.49)$ & $<\mathbf{0 . 0 0 1}$ \\
$\geq 200(n=289)$ & $93(32.2)$ & $4.57(2.71-7.71)$ & $<\mathbf{0 . 0 0 1}$ \\
\hline
\end{tabular}

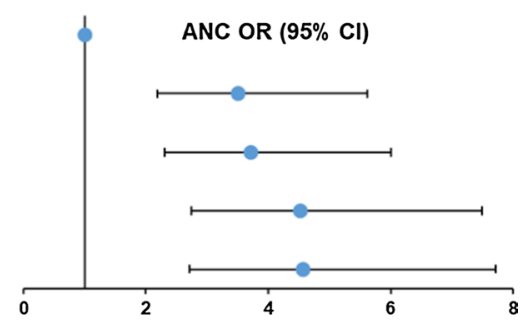

\begin{tabular}{llcc}
\hline $\begin{array}{l}\text { Admission BG levels } \\
\mathbf{m g} / \mathrm{dl}\end{array}$ & $\begin{array}{l}\text { Major infection, } \\
\boldsymbol{n}(\%)\end{array}$ & $\begin{array}{c}\text { Adjusted OR } \\
\mathbf{( 9 5 \%} \mathrm{Cl})\end{array}$ & $\begin{array}{c}\text { Adjusted } \\
\boldsymbol{P} \text { value }\end{array}$ \\
\hline$\geq 70$ to $126(n=285)$ & $23(8.1)$ & 1 (reference) & - \\
$\geq 126(n=682)$ & $117(17.2)$ & $2.22(1.37-3.60)$ & $\mathbf{0 . 0 0 1}$ \\
$\geq 140(n=579)$ & $104(18.0)$ & $2.32(1.42-3.78)$ & $\mathbf{0 . 0 0 1}$ \\
$\geq 180(n=366)$ & $84(23.0)$ & $3.36(2.00-5.64)$ & $<\mathbf{0 . 0 0 1}$ \\
$\geq 200(n=289)$ & $70(24.2)$ & $3.63(2.12-6.21)$ & $<\mathbf{0 . 0 0 1}$ \\
\hline
\end{tabular}

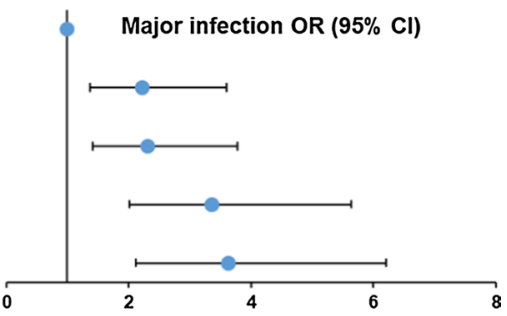

\begin{tabular}{llcc}
\hline $\begin{array}{l}\text { Admission BG levels } \\
\text { mg/dl }\end{array}$ & $\begin{array}{l}\text { Mortality, } \\
\boldsymbol{n}(\%)\end{array}$ & $\begin{array}{c}\text { Adjusted OR } \\
(\mathbf{9 5 \%} \text { Cl) }\end{array}$ & $\begin{array}{c}\text { Adjusted } \\
\boldsymbol{P} \text { value }\end{array}$ \\
\hline$\geq 70$ to $126(n=285)$ & $1(0.4)$ & 1 (reference) & - \\
$\geq 126(n=682)$ & $52(7.6)$ & $19.19(2.63-140.18)$ & $\mathbf{0 . 0 0 4}$ \\
$\geq 140(n=579)$ & $48(8.3)$ & $20.75(2.83-152.05)$ & $\mathbf{0 . 0 0 3}$ \\
$\geq 180(n=366)$ & $40(10.9)$ & $28.78(3.89-213.04)$ & $\mathbf{0 . 0 0 1}$ \\
$\geq 200(n=289)$ & $32(11.1)$ & $28.98(3.86-217.42)$ & $\mathbf{0 . 0 0 1}$ \\
\hline
\end{tabular}

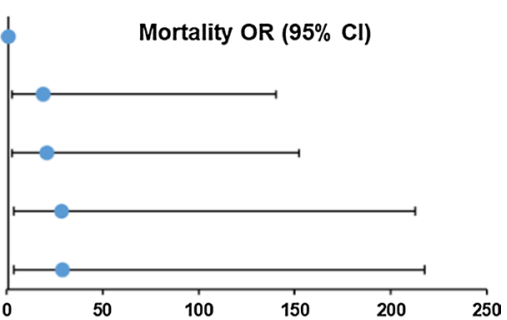

B Pre-existing diabetes

\begin{tabular}{llcc}
\hline $\begin{array}{l}\text { Admission BG levels, } \\
\mathbf{~ m g / d l}\end{array}$ & $\begin{array}{l}\text { POF, } \\
\boldsymbol{n}(\%)\end{array}$ & $\begin{array}{c}\text { Adjusted OR } \\
\mathbf{( 9 5 \% ~ C l )}\end{array}$ & $\begin{array}{c}\text { Adjusted } \\
\mathbf{P} \text { value }\end{array}$ \\
\hline$\geq 70$ to $180(n=27)$ & $8(29.6)$ & 1 (reference) & - \\
$\geq 180(n=87)$ & $38(43.7)$ & $2.21(0.73-6.70)$ & 0.161 \\
$\geq 250(n=58)$ & $31(53.4)$ & $3.10(0.93-10.36)$ & 0.067 \\
$\geq 300(n=40)$ & $26(65.0)$ & $7.54(1.66-34.27)$ & $\mathbf{0 . 0 0 9}$ \\
$\geq 350(n=21)$ & $16(76.2)$ & $17.18(2.05-144.01)$ & $\mathbf{0 . 0 0 9}$ \\
\hline
\end{tabular}

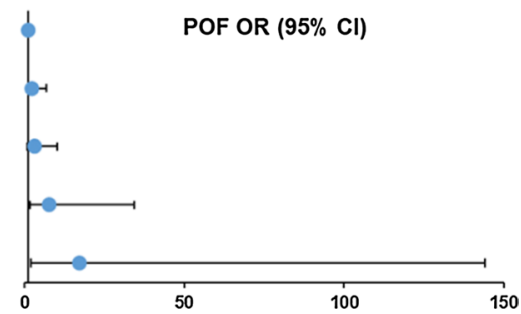


4Fig. 3 Trend analysis for clinical outcomes stratified by different stress hyperglycemia definitions in the non-diabetes (a) and diabetes (b). $B G$ blood glucose, $P O F$ persistent organ failure, $O R$ odds ratio, $C I$ confidence interval, $A N C$ acute necrotic collection

independently associated with POF, ANC, major infection, and mortality.

\section{Comparison of ROC Curves}

Previous studies have reported a significant association between admission blood urea nitrogen (BUN) levels and their changes during the first $24 \mathrm{~h}$ with severity of AP [25, 26]. The predictive values of admission BG and BUN levels as well as their respective changes during the first $24 \mathrm{~h}$ (635 [58.7\%] patients had complete data) for POF were compared (Supplementary Fig. S2). The AUCs for admission BG $(0.71,95 \%$ CI $0.67-0.74)$ and BUN $(0.69,95 \%$ CI 0.65-0.73) were comparable, both were higher than changes in BG $(0.63,95 \%$ CI $0.60-0.67)$ and BUN $(0.56,95 \%$ CI $0.52-0.60$ ) during the first $24 \mathrm{~h}$.

The Glasgow score included glucose $>180 \mathrm{mg} / \mathrm{dl}$ as a parameter [12], which is equivalent to definition of stress hyperglycemia for no pre-existing DM patients. Systemic inflammatory response syndrome (SIRS) score is recommended by the International Association of Pancreatology/ American Pancreatic Association (IAP/APA) practice guidelines [27] for early prediction of POF. The prediction effect of BG alone, SIRS and Glasgow for POF by ROC curves are shown in Fig. 4. The AUC for Glasgow score $(0.81,95 \%$ CI $0.78-0.83)$ was significantly higher than BG alone $(0.73$, $95 \%$ CI $0.70-0.75, P<0.001)$ and SIRS score $(0.77,95 \%$ CI $0.74-0.80, P=0.033)$. And SIRS score also showed higher prognostic power than $\mathrm{BG}$ alone $(P=0.025)$. When $\mathrm{BG}$ and SIRS were combined, the AUC $(0.81,95 \%$ CI $0.79-0.84)$ was similar to Glasgow score alone $(P=0.665)$. The results revealed the combination of BG and SIRS was effective in early prediction of POF.

\section{Discussion}

The study investigated the relationship of DM and stress hyperglycemia with clinical outcomes of AP. No significant differences were observed between AP patients with and without pre-existing DM. After defining different cut-off values of stress hyperglycemia, BG level of $\geq 180 \mathrm{mg} / \mathrm{dl}$ and $\geq 300 \mathrm{mg} / \mathrm{dl}$ were selected to provide a better definition of stress hyperglycemia in AP patients without and with DM, respectively. In multivariate logistic analysis, stress hyperglycemia was independently associated with POF, ANC, major infection and mortality. In addition, the combination of admission BG and SIRS significantly increased the predictive values compared with SIRS alone for POF, this combination was also superior to Glasgow score alone.

The endocrine pancreas has been increasingly recognized in relation to exocrine pancreatic diseases [28, 29]. Previous population-based studies suggested an increased risk for AP in patients with comorbid DM [30,31], but there is a lack of consensus on whether DM aggravates the severity of AP. A recent systematic review and meta-analysis [32] demonstrated that patients with AP and diabetes had an increased risk of renal failure, local complications and mortality compared to non-diabetics. In our study, it appeared that the clinical outcomes were not significantly different between diabetic and non-diabetic patients, similar to findings from a study involving 7399 Pennsylvanian AP patients [33]. Moreover, some studies report that pre-existing T2DM is associated with a lower risk of hospital mortality in AP patients [15, 34]. An alternative explanation is the beneficial effect of interventions and improved lifestyle in diabetic patients $[8,35,36]$.

While the extent to which pre-existing DM may increase the severity of AP remained undetermined, the association between stress hyperglycemia and adverse outcomes seemed to be certain. There was a significantly higher admission BG levels in AP patients with pre-existing DM than those without ( 252 vs. $153 \mathrm{mg} / \mathrm{dl}, P<0.001)$, which suggested a separate and higher cut-off value for stress hyperglycemia should be considered in patients with comorbid DM. Actually, stress hyperglycemia was usually found in patients without known pre-existing DM, and there is no agreed definition of stress hyperglycemia in different acute and critical illnesses $[8,37]$. Dungan et al. defined stress hyperglycemia as fasting plasma glucose levels $\geq 126 \mathrm{mg} / \mathrm{dl}$ for non-diabetic patients [8], and the definition varies in different studies, such as myocardial infarction $(\geq 110, \geq 120, \geq 140, \geq 144$, $\geq 180$, or $\geq 200 \mathrm{mg} / \mathrm{dl}$ ) $[9,38]$, surgery $(\geq 140$ or $\geq 180 \mathrm{mg} /$ dl) $[11,39-41]$ and critical illness ( $\geq 126$ or $\geq 200 \mathrm{mg} / \mathrm{dl}$ ) [42, 43]. In our study, we defined stress hyperglycemia for non-diabetic patients as $\geq 126, \geq 140, \geq 180$, and $\geq 200 \mathrm{mg} /$ $\mathrm{dl}$, and selected a cut-off BG level of $\geq 180 \mathrm{mg} / \mathrm{dl}$ to provide a better definition according to multivariate logistic regression and ROC curves. The results were consistent with Glasgow score, which used a cut-off values for admission BG $(>180 \mathrm{mg} / \mathrm{dl})$ and suggested higher glycemic levels were associated with worse clinical outcomes [12].

We also assessed whether the definition of stress hyperglycemia for non-diabetic patients (BG level $\geq 180 \mathrm{mg} / \mathrm{dl}$ ) makes sense in diabetic patients. Although the relationship between stress hyperglycemia and adverse outcomes was significantly meaningful in AP patients without DM, the differences were not mirrored in patients with pre-existing DM. These findings corroborated with previous studies in acute myocardial infarction where a similar significant association 
Table 3 Multivariate logistic regression of risk factors for POF, ANC, major infection, and mortality

\begin{tabular}{|c|c|c|c|c|c|c|c|c|}
\hline \multirow[t]{2}{*}{ Variables } & \multicolumn{2}{|l|}{ POF } & \multicolumn{2}{|l|}{ ANC } & \multicolumn{2}{|l|}{ Major infection } & \multicolumn{2}{|l|}{ Mortality } \\
\hline & OR $(95 \% \mathrm{CI})$ & $P$ value & OR $(95 \% \mathrm{CI})$ & $P$ value & OR $(95 \% \mathrm{CI})$ & $P$ value & OR $(95 \% \mathrm{CI})$ & $P$ value \\
\hline Age ( $>60$ vs. $\leq 60$ years old $)$ & $1.99(1.37-2.89)$ & $<0.001$ & $0.78(0.50-1.22)$ & 0.269 & $2.00(1.28-3.13)$ & 0.002 & $2.89(1.39-6.02)$ & 0.005 \\
\hline Gender (male vs. female) & $1.36(1.01-1.84)$ & 0.042 & $1.19(0.86-1.65)$ & 0.300 & $1.57(1.07-2.31)$ & 0.020 & $1.26(0.70-2.28)$ & 0.446 \\
\hline $\begin{array}{l}\text { Charlson comorbidity index } \\
\text { (>1 vs. } \leq 1)\end{array}$ & $1.80(1.17-2.75)$ & 0.007 & $1.23(0.77-1.97)$ & 0.388 & $1.07(0.62-1.84)$ & 0.818 & $0.74(0.30-1.81)$ & 0.511 \\
\hline Referral status (yes vs. no) & $2.93(1.90-4.52)$ & $<0.001$ & $3.11(1.81-5.36)$ & $<0.001$ & $2.35(1.32-4.19)$ & 0.004 & $2.71(0.95-7.77)$ & 0.063 \\
\hline $\begin{array}{l}\text { Time to admission ( } \geq 24 \text { vs. } \\
<24 \mathrm{~h})\end{array}$ & $1.49(1.11-2.00)$ & 0.008 & $1.53(1.10-2.14)$ & 0.012 & $1.38(0.95-2.02)$ & 0.093 & $1.83(0.98-3.43)$ & 0.060 \\
\hline $\begin{array}{l}\text { Admission HTG (TG lev- } \\
\text { els } \geq 500 \text { vs. }<500 \mathrm{mg} / \mathrm{dl} \text { ) }\end{array}$ & $1.28(0.93-1.77)$ & 0.132 & $1.05(0.74-1.49)$ & 0.768 & $0.84(0.55-1.27)$ & 0.397 & $1.94(1.01-3.75)$ & 0.048 \\
\hline $\begin{array}{l}\text { Admission stress hyperglycae- } \\
\text { mia (yes vs. no) }\end{array}$ & $3.45(2.59-4.60)$ & $<0.001$ & $2.37(1.73-3.26)$ & $<0.001$ & $2.80(1.95-4.04)$ & $<0.001$ & $4.30(2.32-7.99)$ & $<0.001$ \\
\hline
\end{tabular}

$P O F$ persistent organ failure, $A N C$ acute necrotic collection, $O R$ odds ratio, $C I$ confidence interval, $H T G$ hypertriglyceridaemia, $T G$ triglyceride

Fig. 4 Comparison of receiver operating characteristic curves for prediction of POF at admission. $P O F$ persistent organ failure, $B G$ blood glucose, SIRS systemic inflammatory response syndrome, $A U C$ area under the curve, $C I$ confidence interval
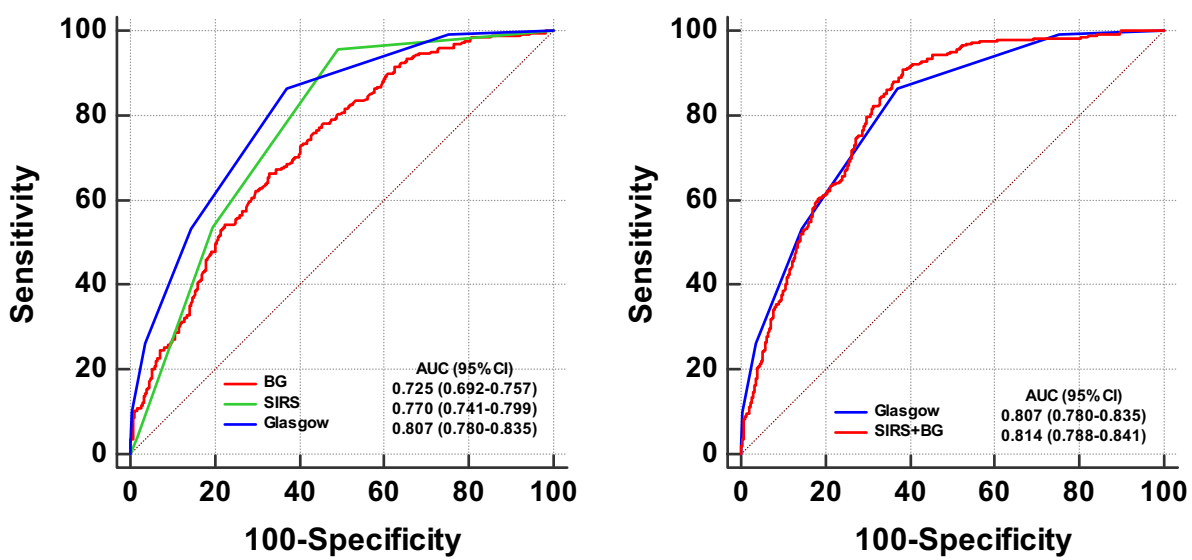

was found in patients without DM, but was not clearly established in DM [44, 45]. The impact of acute hyperglycemia may be more pronounced in patients without diabetes than in those with DM, suggesting that the extent and may be the rate of glucose changes from baseline and not the absolute glucose concentration could be more detrimental. When defined stress hyperglycemia for diabetic patients as BG levels $\geq 180, \geq 250, \geq 300$, and $\geq 350 \mathrm{mg} / \mathrm{dl}$ ) based on previous study of trauma patients [46], only BG level $\geq 300 \mathrm{mg} / \mathrm{dl}$ was shown to be associated with POF. The results were further validated in the ROC curves and the best cut-off value was very close $(295 \mathrm{mg} / \mathrm{dl})$.

Potential mechanisms have been proposed for the association of stress hyperglycemia and poorer outcomes of patients with AP. Stress hyperglycemia is part of the acute stress response and is mediated primarily by stimulation of the hypothalamic-pituitary-adrenal axis and autonomic nervous system, causing release of counter regulatory hormones (e.g. noradrenaline, glucagon, cortisol, growth hormone) and cytokines (e.g. tumor necrosis factor-alpha and interleukin-1). During stress, the complex interplay of feedforward and feedback mechanisms between hormones and cytokines results in accelerated hepatic gluconeogenesis and insulin resistance [8]. This acute neurohormonal adaptation provides substrates and energy for fight-or-flight responses, but may have deleterious effects [47]. Experimental and clinical evidence has shown that stress hyperglycaemia can induce intracellular glucose overload and acute glucotoxicity, contributing to oxidative stress, inflammation, endothelial dysfunction, coagulation, osmotic diuresis, inhibition of vasodilatation and impaired ischemic preconditioning. These effects increase the likelihood of organ failure, shock, infection, mortality and longer length of hospital stay in acute and critical illness [44, 45, 47-49]. The acute and long-term responses may vary among patients due to differing glucose tolerance as well as type, severity and stage of illness [8]. It is notable that our findings have been made in patients with damage to an organ that has a central role in glucose regulation. AP carries a particular risk of collateral damage to the many islets of Langerhans, greater components of which 
are $\beta$-cells that secrete insulin, for which there is increasing evidence of a protective role in AP [50,51]. Islets are also at risk from an overwhelming release of cytokines during AP, cofactors in the development of hyperglycemia, which in turn may exacerbate the inflammatory response and facilitate a vicious cycle [8].

The existing routine laboratory biomarkers, clinical scoring systems alone or in combination seem to have limited efficacy in predicting POF in AP patients with AUC around 0.75 [12]. Admission BUN alone or its changes during the first $24 \mathrm{~h}$ has been significantly associated with POF and mortality $[25,26]$. Therefore, BUN is widely in employed as a key component by many existing clinical scoring systems [12]. Here, we show that admission BG and BUN both had higher AUC values than their respective changes during the first $24 \mathrm{~h}$. The AUC of rise in BUN (0.56) reported in our study was lower than a previous study $(0.71)$ in predicting POF may attributed to relative lower proportion of patients had persistent renal failure in our cohort [26]. Although it is unclear whether elevated BG levels are a cause or consequence of AP, it might be a useful marker of AP severity. Our results of stress hyperglycemia were similar to previous studies of prognostic clinical systems (Glasgow), indicative a high admission BG levels ( $\geq 180 \mathrm{mg} / \mathrm{dl})$ as a component for predicting POF [12]. As it is easy to use, only SIRS score is advised by IAP/APA guidelines to predict POF and monitor response to initial therapy at admission in combination with comorbid risk factors [27]. Supplementation of admission BG to SIRS score significantly improved the predictive AUC value when compared to SIRS score alone, which is higher than Glasgow score alone. Should these findings be validated, the importance of admission BG as a severity marker will be established.

The ADA has recommended insulin as the preferred treatment for hyperglycaemia in hospitalized patients with or without pre-existing diabetes, to achieve a target glucose range of $140-180 \mathrm{mg} / \mathrm{dl}$ for the majority of critically ill and non-critically ill patients. Recent randomized controlled studies and meta-analyses have shown moderate glycemic control $(<180 \mathrm{mg} / \mathrm{dl})$ is associated with lower rates of mortality and stroke compared with a target glucose $(200 \mathrm{mg} /$ $\mathrm{dl}$ ), whereas no significant additional benefits or increased rates of hypoglycemia and mortality were found with more strict glycemic control $(<140 \mathrm{mg} / \mathrm{dl})$ [52-54]. In our study, we endeavored to maintain BG levels at $140-180 \mathrm{mg} / \mathrm{dl}$, close to the ADA recommendation. We suggest future studies should investigate whether moderate or strict control of hyperglycemia will reduce duration of POF and improve overall prognosis in AP.

Our study has several limitations. First, the lack of HbA1c data impact on the definition of glucose variability, which may have introduced bias. Second, this observational study did not establish a cause-effect relationship between stress hyperglycemia and POF. It is unclear whether an acute rise of glucose level directly contributes to development of POF or is no more than a marker of disease severity. Third, the higher frequency of HTG-AP in our cohorts is different from that typical in Western countries, necessitating caution in the generalization of our findings.

This study of AP patients broadens the previously reported relationship of stress hyperglycemia found in other acute and critical illnesses. We conclude that on hospital admission with AP measurement of glucose, and HbA1c are of major clinical significance and would suggest should be routine and recommended in practice guidelines. Future studies and trials are needed to evaluate the impact of insulin regimens on outcomes in AP patients with stress hyperglycemia.

Supplementary Information The online version contains supplementary material available at https://doi.org/10.1007/s10620-021-06982-8.

Acknowledgments These authors thank all the staff from the pancreas multidisciplinary teams at West China Hospital of Sichuan University for their continuous support. This study was supported by NZ-China Strategic Research Alliance 2016 Award (China: 2016YFE0101800, QX, TJ, WH and LD; New Zealand: JAW and AP); National Science Foundation of China (No. 81973632, WH; No. 81774120, QX; No. $81800575, \mathrm{TL})$.

Author's contributions $\mathrm{XY}$ and RZ contributed equally as co-first authors. XY, RZ, TJ, LY, LL, WC, and LD: acquisition of data. XY and WH: drafting of the manuscript. XY, RZ, PZ, RM, and WH: analysis and interpretation of data. PZ and RMartina: statistical analysis supervision. DD, XF, TL, and JAW: important intelligence input. SP, ARP, VKS, RS, and JAW: critical revision of the manuscript. WH and QX: study concept and design, obtained funding; study supervision.

\section{Declarations}

Conflict of interest RS has provided consultancy to Abbot (Mylan); no further support from any organization for the submitted work; no financial relationships with any organizations that might have had an interest in the submitted work in the previous 3 years; no other relationship or activities that could appear to have influenced the submitted work.

Open Access This article is licensed under a Creative Commons Attribution-NonCommercial 4.0 International License, which permits any non-commercial use, sharing, adaptation, distribution and reproduction in any medium or format, as long as you give appropriate credit to the original author(s) and the source, provide a link to the Creative Commons licence, and indicate if changes were made. The images or other third party material in this article are included in the article's Creative Commons licence, unless indicated otherwise in a credit line to the material. If material is not included in the article's Creative Commons licence and your intended use is not permitted by statutory regulation or exceeds the permitted use, you will need to obtain permission directly from the copyright holder. To view a copy of this licence, visit http://creativecommons.org/licenses/by-nc/4.0/. 


\section{References}

1. Petrov MS, Yadav D. Global epidemiology and holistic prevention of pancreatitis. Nat Rev Gastroenterol Hepatol. 2019;16:175-184.

2. Peery AF, Crockett SD, Murphy CC et al. Burden and cost of gastrointestinal, liver, and pancreatic diseases in the United States: Update 2018. Gastroenterology 2019;156:254-272 e11.

3. Yadav D, Lowenfels AB. The epidemiology of pancreatitis and pancreatic cancer. Gastroenterology 2013;144:1252-1261.

4. Mukherjee R, Nunes QM, Huang W, Sutton R. Precision medicine for acute pancreatitis: current status and future opportunities. Precis Clin Med. 2019;2:81-86.

5. Banks PA, Bollen TL, Dervenis $\mathrm{C}$ et al. Classification of acute pancreatitis-2012: revision of the Atlanta classification and definitions by international consensus. Gut 2013;62:102-111.

6. Moggia E, Koti R, Belgaumkar AP et al. Pharmacological interventions for acute pancreatitis. Cochrane Database Syst Rev. 2017;4:CD011384.

7. Lee PJ, Papachristou GI. New insights into acute pancreatitis. Nat Rev Gastroenterol Hepatol. 2019;16:479-496.

8. Dungan KM, Braithwaite SS, Preiser JC. Stress hyperglycaemia. Lancet. 2009;373:1798-1807.

9. Capes SE, Hunt D, Malmberg K, Gerstein HC. Stress hyperglycaemia and increased risk of death after myocardial infarction in patients with and without diabetes: a systematic overview. Lancet. 2000;355:773-778.

10. Bruno A, Levine SR, Frankel MR et al. Admission glucose level and clinical outcomes in the NINDS rt-PA stroke trial. Neurology. 2002;59:669-674.

11. Kotagal M, Symons RG, Hirsch IB et al. Perioperative hyperglycemia and risk of adverse events among patients with and without diabetes. Ann Surg. 2015;261:97-103.

12. Mounzer R, Langmead CJ, Wu BU et al. Comparison of existing clinical scoring systems to predict persistent organ failure in patients with acute pancreatitis. Gastroenterology. 2012;142:1476-1482 (quiz e15-e16).

13. American Diabetes A. 2. Classification and diagnosis of diabetes: standards of medical care in diabetes-2019. Diabetes Care. 2019;42:S13-S28.

14. Gonzalez-Perez A, Schlienger RG, Rodriguez LA. Acute pancreatitis in association with type 2 diabetes and antidiabetic drugs: a population-based cohort study. Diabetes Care. 2010;33:2580-2585.

15. Mendez-Bailon M, de Miguel Yanes JM, Jimenez-Garcia R et al. National trends in incidence and outcomes of acute pancreatitis among type 2 diabetics and non-diabetics in Spain (20012011). Pancreatology. 2015;15:64-70

16. von Elm E, Altman DG, Egger $M$ et al. Strengthening the reporting of observational studies in epidemiology (STROBE) statement: guidelines for reporting observational studies. BMJ. 2007;335:806-808.

17. American Diabetes A. 15. Diabetes care in the hospital: standards of medical care in diabetes-2019. Diabetes Care. 2019;42:S173-S181.

18. Vipperla K, Somerville C, Furlan A et al. Clinical profile and natural course in a large cohort of patients with hypertriglyceridemia and pancreatitis. J Clin Gastroenterol. 2017;51:77-85.

19. Zhang R, Deng L, Jin T et al. Hypertriglyceridaemia-associated acute pancreatitis: diagnosis and impact on severity. $H P B$ (Oxford). 2019;21:1240-1249.

20. Shi N, Liu T, de la Iglesia-Garcia D et al. Duration of organ failure impacts mortality in acute pancreatitis. Gut. 2020;69:604-605.

21. Qu Z, Fu Q, Xia Q, Cu N. Practical guidelines for management of severe acute pancreatitis by integrated traditional Chinese and western medicine (protocol specifications). Chin J Surg Integr Tradit West Med. 2007;3:232-237.

22. Banks PA, Freeman ML, Practice Parameters Committee of the American College of Gastroenterology. Practice guidelines in acute pancreatitis. Am J Gastroenterol. 2006;101:2379-2400.

23. Clement S, Braithwaite SS, Magee MF et al. Management of diabetes and hyperglycemia in hospitals. Diabetes Care. 2004;27:553-591.

24. Dellinger EP, Forsmark CE, Layer P et al. Determinant-based classification of acute pancreatitis severity: an international multidisciplinary consultation. Ann Surg. 2012;256:875-880.

25. Wu BU, Johannes RS, Sun X, Conwell DL, Banks PA. Early changes in blood urea nitrogen predict mortality in acute pancreatitis. Gastroenterology. 2009;137:129-135.

26. Koutroumpakis E, Wu BU, Bakker OJ et al. Admission hematocrit and rise in blood urea Nitrogen at $24 \mathrm{~h}$ outperform other laboratory markers in predicting persistent organ failure and pancreatic necrosis in acute pancreatitis: a post hoc analysis of three large prospective databases. Am J Gastroenterol. 2015;110:1707-1716.

27. Working Group IAP/APA Acute Pancreatitis Guidelines. IAP/ APA evidence-based guidelines for the management of acute pancreatitis. Pancreatology. 2013;13:e1-15.

28. Czako L, Hegyi P, Rakonczay Z, Jr, Wittmann T, Otsuki M. Interactions between the endocrine and exocrine pancreas and their clinical relevance. Pancreatology. 2009;9:351-359.

29. Meier JJ, Giese A. Diabetes associated with pancreatic diseases. Curr Opin Gastroenterol. 2015;31:400-406.

30. Lai SW, Muo CH, Liao KF, Sung FC, Chen PC. Risk of acute pancreatitis in type 2 diabetes and risk reduction on anti-diabetic drugs: a population-based cohort study in Taiwan. Am J Gastroenterol. 2011;106:1697-1704.

31. Pang Y, Kartsonaki C, Turnbull I et al. Metabolic and lifestyle risk factors for acute pancreatitis in Chinese adults: a prospective cohort study of 0.5 million people. PLoS Med. 2018;15:e1002618.

32. Miko A, Farkas N, Garami A et al. Preexisting diabetes elevates risk of local and systemic complications in acute pancreatitis: systematic review and meta-analysis. Pancreas. 2018;47:917-923.

33. Nawaz H, O'Connell M, Papachristou GI, Yadav D. Severity and natural history of acute pancreatitis in diabetic patients. Pancreatology. 2015;15:247-252.

34. Shen HN, Lu CL, Li CY. Effect of diabetes on severity and hospital mortality in patients with acute pancreatitis: a national population-based study. Diabetes Care. 2012;35:1061-1066.

35. Langouche L, Vanhorebeek I, Vlasselaers D et al. Intensive insulin therapy protects the endothelium of critically ill patients. J Clin Investig. 2005;115:2277-2286.

36. Kikuta K, Masamune A, Shimosegawa T. Impaired glucose tolerance in acute pancreatitis. World J Gastroenterol. 2015;21:7367-7374.

37. Inzucchi SE. Clinical practice. Management of hyperglycemia in the hospital setting. N Engl J Med. 2006;355:1903-1911.

38. Khalfallah M, Abdelmageed R, Elgendy E, Hafez YM. Incidence, predictors and outcomes of stress hyperglycemia in patients with ST elevation myocardial infarction undergoing primary percutaneous coronary intervention. Diab Vasc Dis Res. 2020;17:1479164119883983.

39. Fiorillo C, Quero G, Laterza V et al. Postoperative hyperglycemia affects survival after gastrectomy for cancer: a single-center analysis using propensity score matching. Surgery. 2020;167:815-820.

40. Subramaniam K, Sciortino C, Ruppert K et al. Remifentanil and perioperative glycaemic response in cardiac surgery: an openlabel randomised trial. Br J Anaesth. 2020;124:684-692.

41. Cardona S, Tsegka K, Pasquel FJ et al. Sitagliptin for the prevention of stress hyperglycemia in patients without diabetes undergoing coronary artery bypass graft (CABG) surgery. BMJ Open Diabetes Res Care. 2019;7:e00703. 
42. Plummer MP, Finnis ME, Phillips LK et al. Stress induced hyperglycemia and the subsequent risk of type 2 diabetes in survivors of critical illness. PLOS ONE. 2016;11:e0165923.

43. Ali Abdelhamid Y, Kar P, Finnis ME et al. Stress hyperglycaemia in critically ill patients and the subsequent risk of diabetes: a systematic review and meta-analysis. Crit Care. 2016;20:301.

44. Marenzi G, Cosentino N, Milazzo V et al. Acute kidney injury in diabetic patients with acute myocardial infarction: role of acute and chronic glycemia. J Am Heart Assoc. 2018;7:e008122.

45. Marenzi G, Cosentino N, Milazzo V et al. Prognostic value of the acute-to-chronic glycemic ratio at admission in acute myocardial infarction: a prospective study. Diabetes Care. 2018;41:847-853.

46. Rau CS, Wu SC, Chen YC et al. Stress-induced hyperglycemia in diabetes: a cross-sectional analysis to explore the definition based on the trauma registry data. Int J Environ Res Public Health. 2017; $14: 1527$.

47. Boonen E, Van den Berghe G. Endocrine responses to critical illness: novel insights and therapeutic implications. J Clin Endocrinol Metab. 2014;99:1569-1582.

48. Monnier L, Mas E, Ginet $\mathrm{C}$ et al. Activation of oxidative stress by acute glucose fluctuations compared with sustained chronic hyperglycemia in patients with type 2 diabetes. JAMA. 2006;295:1681-1687.

49. Vanhorebeek I, Langouche L, Van den Berghe G. Glycemic and nonglycemic effects of insulin: How do they contribute to a better outcome of critical illness? Curr Opin Crit Care. 2005;11:304-311.
50. Mankad P, James A, Siriwardena AK, Elliott AC, Bruce JI. Insulin protects pancreatic acinar cells from cytosolic calcium overload and inhibition of plasma membrane calcium pump. J Biol Chem. 2012;287:1823-1836.

51. Samad A, James A, Wong J et al. Insulin protects pancreatic acinar cells from palmitoleic acid-induced cellular injury. J Biol Chem. 2014;289:23582-23595.

52. Investigators N-SS, Finfer S, Chittock DR et al. Intensive versus conventional glucose control in critically ill patients. $N$ Engl J Med. 2009;360:1283-1297.

53. Sathya B, Davis R, Taveira T, Whitlatch H, Wu WC. Intensity of peri-operative glycemic control and postoperative outcomes in patients with diabetes: a meta-analysis. Diabetes Res Clin Pract. 2013;102:8-15.

54. Umpierrez G, Cardona S, Pasquel F et al. Randomized controlled trial of intensive versus conservative glucose control in patients undergoing coronary artery bypass graft surgery: GLUCO-CABG trial. Diabetes Care. 2015;38:1665-1672.

Publisher's Note Springer Nature remains neutral with regard to jurisdictional claims in published maps and institutional affiliations. 